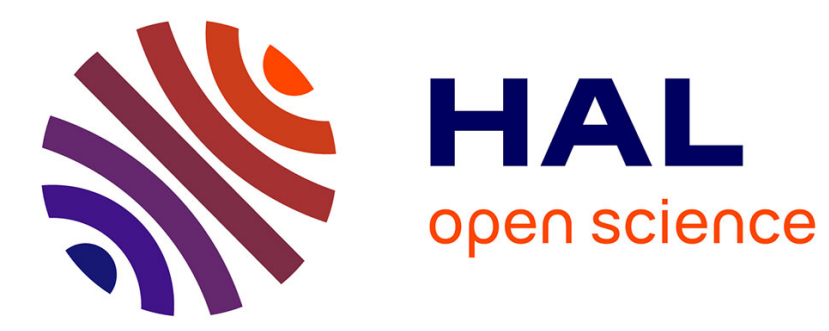

\title{
Aging of Registered Voters and Voter Turnout in France: A Study of 17 Voting Rounds between 2002 and 2012
}

\author{
Jean-Yves Dormagen, Laura Michel
}

\section{To cite this version:}

Jean-Yves Dormagen, Laura Michel. Aging of Registered Voters and Voter Turnout in France: A Study of 17 Voting Rounds between 2002 and 2012. The Australian Political Studies Association Annual Conference, University of Sydney, Australia, Sep 2014, Sydney, Australia. 10.2139/ssrn.2440506 . hal-02613343

\section{HAL Id: hal-02613343 \\ https://hal.science/hal-02613343}

Submitted on 20 May 2020

HAL is a multi-disciplinary open access archive for the deposit and dissemination of scientific research documents, whether they are published or not. The documents may come from teaching and research institutions in France or abroad, or from public or private research centers.
L'archive ouverte pluridisciplinaire HAL, est destinée au dépôt et à la diffusion de documents scientifiques de niveau recherche, publiés ou non, émanant des établissements d'enseignement et de recherche français ou étrangers, des laboratoires publics ou privés.

\section{다)(1) $(5$}

Distributed under a Creative Commons Attribution - NonCommercial| 4.0 International 
From Intermittent Behavior in Youth to the Consistency of Very Old Age

Aging of Registered Voters and Voter Turnout in France: A Study of 17 Voting Rounds between 2002 and 2012

Jean-Yves Dormagen and Laura Michel, Université de Montpellier

\section{Introduction}

Due to the rapid aging of the population, issues of voting behavior among older adults and even more among the "oldest old" have gained crucial statistical and political importance. A few figures suffice to gauge this. In France, for the 2002 presidential election, those over 80 still accounted for only $5.1 \%$ of registered voters. This proportion doubled in the space of 10 years. In the last presidential election, in 2012, the over 80 made up $10 \%$ of registered voters, in other words a proportion that now exceeds the 18-24 age group. The "oldest old" has thus become a decisive segment of the electorate.

Our current research focuses on the voting behavior of these very old voters. In this communication, we will also try to deepen our understanding of the relationship between aging and voter turnout: do these very old voters continue to vote in large numbers? Do they vote more or less often than the average? Do they remain consistent voters or on the contrary, do they adopt an intermittent behavior? Are they sensitive to the intensity of election campaigns? Are major differences in voting behavior observed between old age (60-79) and the oldest old (over 80 )? Is it possible to identify turnout differences within the oldest old category, between the less elderly of the very old and the oldest of the very old?

The academic literature has long since established that there is a strong correlation between age and voter turnout (Beck, Jennings, 1982, Buds, Stokes, 1974, Campbell, Converse, Miller, Stokes, 1960, Lipset, Lazarsfeld, Barton, Linz, 1954, Riley, Foner, 1978). The shape of the curve produced by this correlation is moreover fairly similar in nearly all the major democracies. Overall, abstention is higher in the younger age groups of the electorate. Then turnout increases over time, generally reaching its highest rate among the segments made up of the middle-aged workforce and young retirees (Denni, 2012, Nie, Verba, 1972). An increase in abstention is then noted with the approach of very old age and even more so among the oldest old, who increasingly refrain from going to the polls as they age to the point of becoming the largest non-voting segment of the electorate.

The hypothesis we would like to test here is indeed one of an "age effect" that is apparent in more or less direct forms throughout voting life and helps to better understand the nature of voter turnout (Goerres, 2009). The effect can be formulated as follows: aging produces greater behavioral consistency, confirmed by voting behavior (among other things). Testing this effect amounts to verifying that intermittence (alternating between voting and abstention) decreases with age and that this general evolution resulting from aging is not contradicted by the behavior of the oldest old of older adults. 


\section{Methods and data}

Traditional questionnaire surveys are generally an inadequate tool for tackling such hypotheses and especially for analyzing differences in voter turnout related to aging within the old age and oldest old age groups. First for a general reason: respondents are known to considerably over-report their votes, which consequently makes it particularly difficult to analyze abstention. For reasons more directly related to our topic of investigation, secondly, because sample sizes are almost always too small to allow narrow segmentation by small age groups (for instance by distinguishing the 80-84 age group from those over 85 ) and thus identify behavior differences within the oldest old with precision. Problems of method are further heightened in this case by the unrepresentative nature of seniors who agree to take part in this type of survey: it involuntarily has a selection effect that produces an overrepresentation of the most active, the best socially integrated and the most physically able of retirees. This selection bias tends to increase with age and is thus likely to have a particularly heavy impact on studies of the oldest seniors. Lastly, to study the evolution of consistency in voter turnout, it is preferable to use panel surveys, the only type that is able to identify the more or less intermittent or on the contrary consistent nature of abstention and participation at an individual level. Such panels are rare in the French context and tend to amplify the methodological biases just mentioned. The selective mortality affecting them not only leads to a considerable drop in sample size (from 4000 individuals at the start to about 1500 after three survey waves) but also an increase in selection biases making it difficult to test the hypotheses that interest us: an even lower proportion of the oldest old in the final sample and increased overrepresentation of the most active among them.

To get around these limits and biases, we chose to conduct our analyses on the basis of data collected by an alternative method: by exploiting the databases derived from INSEE (the French National Institute of Statistics and Economic Studies) electoral participation surveys. Such surveys have been conducted for every presidential election since 1988. The first advantage of them lies in sample size: the samples comprise about one-thousandth of the registered voters in metropolitan France. The samples are therefore very large in size: 39,155 individuals for the sample covering the 2002 presidential election, 32,121 for the 2007 election and 39,728 for the 2012 election. The sizes of these sample bases make it possible to achieve a very narrow stratification of the population. It is thus possible to conduct an analysis on small age groups (spanning 5 years, for instance), while preserving excellent statistical significance. INSEE samples also display a remarkable degree of representativeness. This is mainly ensured by the fact that the individuals making up the samples are directly selected at random from the national electoral roll listing all registered voters in France (also administered by INSEE). Since sampling is performed at random and there is no need to seek the consent of the voters who comprise the sample, selection bias is considerably reduced. This is a considerable advantage in particular as regards the study of voter disengagement among the oldest segments of the population, who are all the less likely to be included in traditional survey-taking systems as they are more physically diminished and more socially isolated. Another methodological advantage is that some of the data in INSEE databases are produced directly from electoral rolls. This is the case of voter age and gender, data which are directly available in the national electoral roll. Likewise, election turnout is directly noted by INSEE survey-takers on the basis of signatures placed on the electoral register by voters themselves on election day. These turnout data are thus also 
highly reliable as they are not declarative and thus not subject to the risk of over-reporting that generally affects voter turnout surveys.

INSEE databases also contain a wealth of sociological information: voters' educational level, marital status and socio-occupational category, for instance. These data are taken from the French population census carried out solely by INSEE. Unlike the preceding data, they were produced by questionnaires administered in the respondents' homes by INSEE survey-takers. They are thus more likely to be subject to selection or declaration bias. It should be pointed out, however, that answering INSEE survey-takers is a legal obligation and census data are, probably for this reason, of good quality. The main shortcoming of these data lies in the sometimes considerable time lag between the date of census and the date of the election studied. Thus, the sociological data that can be used to study voter behavior during the 2007 elections were recorded on the occasion of the 1999 census. While this problem of course does not concern age and certain information such as educational level is rather unlikely to change within a short time, on the other hand occupational category or form of cohabitation (living alone or with a partner, with or without children, etc.) may have undergone considerable changes between the date the census was taken and the date of the election studied. The problem is less significant for the 2002 election as the census data were only three years old. The same holds true for 2012, as census data were collected in 2009.

Our research is thus based primarily on secondary data analysis. However, we have also helped to enrich these sample bases, in partnership with INSEE, by producing data regarding the improper registration of voters for the 2012 elections. Without going into detail here, the system of registering to vote in France is particularly inconvenient, and thus has a significant impact on the likelihood of voter turnout. Each time voters move, they must go through a specific procedure with the municipal authorities to re-register to vote at their new place of residence. This procedure must take place the year prior to the election. Thus, to vote in the presidential election in their new town of residence on April 22 and May 5, 2012, voters who had moved had to re-register at the town hall by December 31, 2011. Many voters do not complete this procedure and become improperly registered: they are registered on the electoral rolls but at a different address from the one where they actually reside. We estimate that $15 \%$ of the electorate is in this situation. Improper registration encourages abstention. It is strongly correlated with voter age: the younger voters are more mobile and thus also the most often improperly registered. This is why analysis of the relationship between age and voter turnout stands to gain by taking into account such a variable.

To conclude the presentation of our methodology, we should also point out that the French electoral system lends itself particularly well to longitudinal studies that can measure the more or less intermittent nature of voting behavior and identify possible relationships between the level of intensity of an election and the turnout probability of various age groups making up the electorate. A characteristic of France its large number of voting rounds held in elections of highly varying intensity. This is explained by the number of elections, the fact that most of them are set up as two-ballot rounds and the fact that these different elections are not grouped together in time (as is the case in the United States and Brazil, for instance) but on the contrary each held on specific dates. As a result, voting takes place in France nearly every year and often several times in the same year. Thus, during the 2002-2012 period that we have used here as the framework for our study, there were only two years without a national election: in 2006 and 2011, in which only a portion of voters were concerned in the context of cantonal by-elections. In the space of 11 years, voters were thus called to 
the polls 21 times. These 21 rounds of balloting show very different turnout rates: record levels such as in the two ballots of the 2007 presidential election when $84 \%$ of registered voters went to the polls, but also low rates such as for the 2009 European elections (40.6\%) and the 2010 regional elections (48.8\%) or average rates, such as for the 2007 legislative elections $(60.2 \%)$ and the 2008 municipal elections (65.8\%). These repeated rounds of balloting and the high variation in turnout rates thus provides a particularly suitable observatory to study voter intermittence and test our hypotheses regarding increasing consistency in relation to voter aging. The three INSEE sample bases we used are in this regard very well adapted to this type of necessarily longitudinal approach. Voter turnout is in fact monitored over a series of elections and thus of voting rounds spread over several years in succession. The first sample base includes 7 successive rounds of balloting: the two ballots of the presidential election and the two ballots of the 2002 legislative elections as well as the two ballots of the regional elections and the single round of European elections in 2004. The second sample base includes 6 successive rounds of balloting: the two ballots of the presidential election and the two ballots of the 2007 legislative elections as well as the two ballots of the 2008 municipal elections. The third and last sample base includes the two ballots of the 2012 presidential election and the two ballots of the 2012 legislative elections. To explore the relationships between age and voter turnout, a total of 17 voting rounds will thus be analyzed. These three sample bases enable us to undertake a meticulous comparison of the logics of voter turnout in three institutionally identical sequences including two rounds of presidential election and two rounds of legislative elections (2002, 2007 and 2012) with the advantage of establishing the logics of turnout by age group in three very different political circumstances: the victory of a right-wing candidate (UMP) in 2002 and 2007, and the victory of the left in 2012 (Socialist Party). The repetition of the electoral sequences taken into consideration should thus neutralize possible effects of political circumstances to better identify possible regularities in the relationships between age and voter turnout.

Results

Longitudinal observation of turnout in the 17 voting rounds between 2002 and 2012 included in this study confirms the relationships we expected to find between age groups and voter turnout rate (table 1) and helps to define them more precisely. It first of all confirms that turnout increases continually from the younger age groups (18-24 and 25-29) until the younger segments of older adults where it plateaus at age 65-69 before declining noticeably among members of the oldest old group which after age 84 is the age group with the highest non-voting rate. The average turnout rates recorded for these 17 voting rounds thus show considerable differences: $52.2 \%$ of the $18-24$ and the $25-29$ age groups turned out to vote on average, $80.8 \%$ of the $65-69$-year-olds and $47.8 \%$ of the over 84 . The average turnout rate for the $65-69$ is thus 28.6 percentage points higher than the rate for those age 18-29 and 33 points higher than the rate for the over 84 . The pace of the increase in turnout is particularly interesting. It remains very stable within the first two age groups (18-24 and 25-29) at about 52\%. Then it experiences a rapid rate of increase in the thirties: 7.1 percentage points in the 30-34 age group then again 7.2 more percentage points among the 35-39. Compared to the twenties, the thirties is a decade in which voter turnout rises by 14.3 percentage points. 
Table 1 - Turnout and deviation from the mean by age group established for 17 voting rounds between 2002 and 2012

\begin{tabular}{|c|c|c|c|c|c|c|c|c|c|c|c|c|c|c|c|c|c|c|c|}
\hline 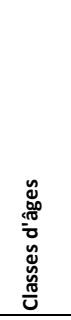 & 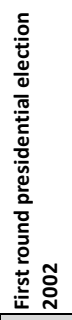 & 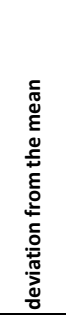 & 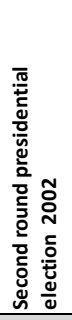 & 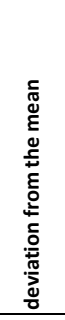 & 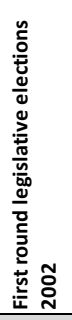 & 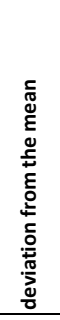 & 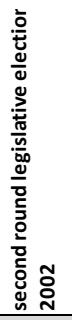 & 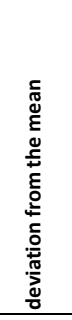 & 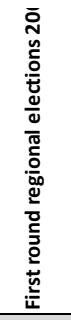 & 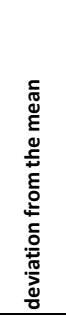 & 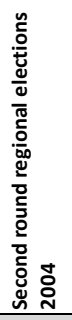 & 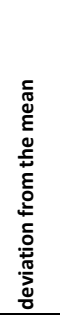 & 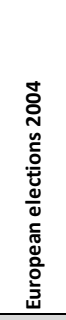 & 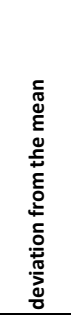 & 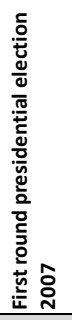 & 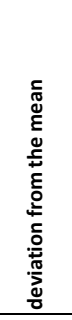 & 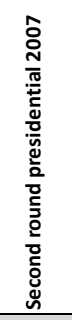 & 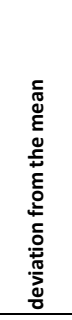 & 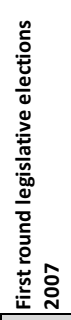 \\
\hline $18-24$ & $66,8 \%$ & $14,7 \%$ & $77,2 \%$ & $25,1 \%$ & $50,1 \%$ & $-2,0 \%$ & $45,2 \%$ & $-6,9 \%$ & $43,9 \%$ & $-8,2 \%$ & $46,5 \%$ & $-5,6 \%$ & $26,3 \%$ & $-25,8 \%$ & $78,7 \%$ & $26,6 \%$ & $78,1 \%$ & $26,0 \%$ & $39,3 \%$ \\
\hline $25-29$ & $62,2 \%$ & $9,8 \%$ & $71,4 \%$ & $19,0 \%$ & $50,4 \%$ & $-2,0 \%$ & $42,2 \%$ & $-10,2 \%$ & $43,5 \%$ & $-8,9 \%$ & $45,6 \%$ & $-6,8 \%$ & $25,5 \%$ & $-26,9 \%$ & $81,6 \%$ & $29,2 \%$ & $79,9 \%$ & $27,5 \%$ & $42,8 \%$ \\
\hline 30-34 & $68,7 \%$ & $9,2 \%$ & $78,3 \%$ & $18,8 \%$ & $55,1 \%$ & $-4,4 \%$ & $49,8 \%$ & $-9,7 \%$ & $51,2 \%$ & $-8,3 \%$ & $52,2 \%$ & $-7,3 \%$ & $30,6 \%$ & $-28,9 \%$ & $84,8 \%$ & $25,3 \%$ & $85,0 \%$ & $25,5 \%$ & $51,3 \%$ \\
\hline 35-39 & $71,8 \%$ & $5,1 \%$ & $82,1 \%$ & $15,4 \%$ & $62,5 \%$ & $-4,2 \%$ & $56,1 \%$ & $-10,6 \%$ & $59,2 \%$ & $-7,5 \%$ & $62,9 \%$ & $-3,8 \%$ & $36,9 \%$ & $-29,8 \%$ & $88,5 \%$ & $21,8 \%$ & $87,5 \%$ & $20,8 \%$ & $58,7 \%$ \\
\hline $40-44$ & $76,4 \%$ & $6,1 \%$ & $84,9 \%$ & $14,6 \%$ & $66,0 \%$ & $-4,3 \%$ & $61,1 \%$ & $-9,2 \%$ & $65,0 \%$ & $-5,3 \%$ & $68,0 \%$ & $-2,3 \%$ & $40,0 \%$ & $-30,3 \%$ & $87,8 \%$ & $17,5 \%$ & $88,5 \%$ & $18,2 \%$ & $64,7 \%$ \\
\hline $45-49$ & $77,0 \%$ & $3,7 \%$ & $84,6 \%$ & $11,3 \%$ & $70,4 \%$ & $-2,9 \%$ & $65,9 \%$ & $-7,4 \%$ & $68,7 \%$ & $-4,6 \%$ & $73,0 \%$ & $-0,3 \%$ & $48,5 \%$ & $-24,8 \%$ & $89,3 \%$ & $16,0 \%$ & $89,9 \%$ & $16,6 \%$ & $67,7 \%$ \\
\hline 50-54 & $78,0 \%$ & $2,3 \%$ & $86,7 \%$ & $11,0 \%$ & $73,4 \%$ & $-2,3 \%$ & $69,1 \%$ & $-6,6 \%$ & $69,6 \%$ & $-6,1 \%$ & $72,8 \%$ & $-2,9 \%$ & $49,6 \%$ & $-26,1 \%$ & $90,9 \%$ & $15,2 \%$ & $90,4 \%$ & $14,7 \%$ & $70,5 \%$ \\
\hline 55-59 & $79,6 \%$ & $2,1 \%$ & $86,2 \%$ & $8,7 \%$ & $74,7 \%$ & $-2,8 \%$ & $71,3 \%$ & $-6,2 \%$ & $71,3 \%$ & $-6,2 \%$ & $76,2 \%$ & $-1,3 \%$ & $53,8 \%$ & $-23,7 \%$ & $90,7 \%$ & $13,2 \%$ & $90,6 \%$ & $13,1 \%$ & $72,6 \%$ \\
\hline $60-64$ & $80,5 \%$ & $1,5 \%$ & $86,1 \%$ & $7,1 \%$ & $76,3 \%$ & $-2,7 \%$ & $72,3 \%$ & $-6,7 \%$ & $73,2 \%$ & $-5,8 \%$ & $77,8 \%$ & $-1,2 \%$ & $56,5 \%$ & $-22,5 \%$ & $91,6 \%$ & $12,6 \%$ & $91,6 \%$ & $12,6 \%$ & $77,0 \%$ \\
\hline 65-69 & $81,1 \%$ & $0,3 \%$ & $87,0 \%$ & $6,2 \%$ & $79,1 \%$ & $-1,7 \%$ & $74,8 \%$ & $-6,0 \%$ & $73,2 \%$ & $-7,6 \%$ & $79,4 \%$ & $-1,4 \%$ & $57,9 \%$ & $-22,9 \%$ & $91,4 \%$ & $10,6 \%$ & $92,1 \%$ & $11,3 \%$ & $76,9 \%$ \\
\hline 70-74 & $77,4 \%$ & $-1,0 \%$ & $83,3 \%$ & $4,9 \%$ & $75,1 \%$ & $-3,3 \%$ & $73,4 \%$ & $-5,0 \%$ & $73,0 \%$ & $-5,4 \%$ & $8,0 \%$ & $-0,4 \%$ & $6,5 \%$ & $1,9 \%$ & $8,6 \%$ & $10,2 \%$ & $87,9 \%$ & $9,5 \%$ & 74,9\% \\
\hline 75-79 & $72,6 \%$ & $-2,7 \%$ & $78,9 \%$ & $3,6 \%$ & $72,0 \%$ & $-3,3 \%$ & $72,5 \%$ & $-2,8 \%$ & $68,3 \%$ & $-7,0 \%$ & $72,7 \%$ & $-2,6 \%$ & $55,7 \%$ & $-19,6 \%$ & $86,5 \%$ & $11,2 \%$ & $87,0 \%$ & $11,7 \%$ & $72,3 \%$ \\
\hline $80-84$ & $67,8 \%$ & $0,3 \%$ & $72,2 \%$ & $4,7 \%$ & $65,7 \%$ & $-1,8 \%$ & $64,8 \%$ & $-2,7 \%$ & $61,8 \%$ & $-5,7 \%$ & $65,2 \%$ & $-2,3 \%$ & $48,2 \%$ & $-19,3 \%$ & $77,9 \%$ & $10,4 \%$ & $79,3 \%$ & $11,8 \%$ & $67,0 \%$ \\
\hline+85 & $40,3 \%$ & $-7,5 \%$ & $47,4 \%$ & $-0,4 \%$ & $40,2 \%$ & $-7,6 \%$ & $40,6 \%$ & $-7,2 \%$ & $38,2 \%$ & $-9,6 \%$ & $43,5 \%$ & $-4,3 \%$ & $29,0 \%$ & $18,8 \%$ & $1,6 \%$ & $13,8 \%$ & $64,8 \%$ & $17,0 \%$ & $0,6 \%$ \\
\hline TOTAL & $72,8 \%$ & $4,2 \%$ & $81,0 \%$ & $12,4 \%$ & $5,1 \%$ & $-3,5 \%$ & $60,8 \%$ & $-7,8 \%$ & $62,5 \%$ & $-6,1 \%$ & $66,2 \%$ & $-2,4 \%$ & $43,9 \%$ & $-24,7 \%$ & $86,2 \%$ & $17,6 \%$ & 86,29 & $17,6 \%$ & 62, \\
\hline
\end{tabular}

\begin{tabular}{|c|c|c|c|c|c|c|c|c|c|c|c|c|c|c|c|c|c|}
\hline 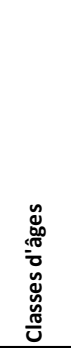 & 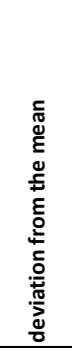 & 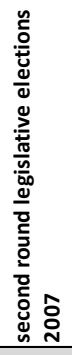 & 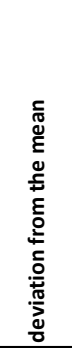 & 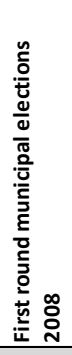 & 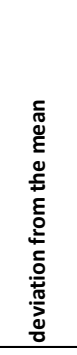 & 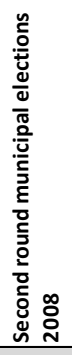 & 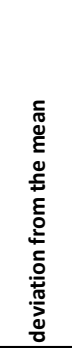 & 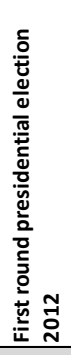 & 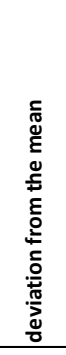 & 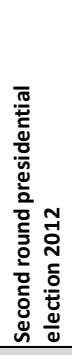 & 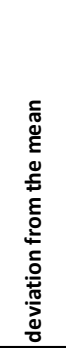 & 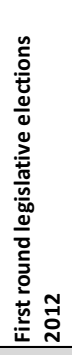 & 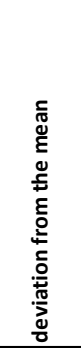 & 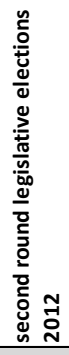 & 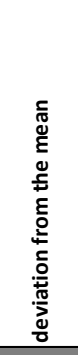 & 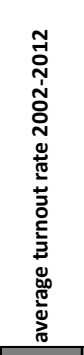 & 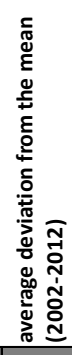 \\
\hline $18-24$ & $-12,8 \%$ & $38,3 \%$ & $-13,8 \%$ & $40,2 \%$ & $-11,9 \%$ & $37,2 \%$ & $-14,9 \%$ & $72,4 \%$ & $20,3 \%$ & $73,3 \%$ & $21,2 \%$ & $37,0 \%$ & $-15,1 \%$ & $35,5 \%$ & $-16,6 \%$ & $52,1 \%$ & $5,7 \%$ \\
\hline $25-29$ & $-9,6 \%$ & $41,6 \%$ & $-10,8 \%$ & $42,4 \%$ & $-10,0 \%$ & $41,1 \%$ & $-11,3 \%$ & $73,0 \%$ & $20,6 \%$ & $72,4 \%$ & $20,0 \%$ & $38,6 \%$ & $-13,8 \%$ & $36,1 \%$ & $-16,3 \%$ & $52,4 \%$ & $1,9 \%$ \\
\hline $30-34$ & $2 \%$ & $48,6 \%$ & $-10,9 \%$ & $54,9 \%$ & $-4,6 \%$ & $50,9 \%$ & $-8,6 \%$ & $79,4 \%$ & $19,9 \%$ & $77,7 \%$ & $18,2 \%$ & $48,6 \%$ & $-10,9 \%$ & $44,7 \%$ & $-14,8 \%$ & $9,5 \%$ & $7 \%$ \\
\hline $35-39$ & $-8,0 \%$ & $58,1 \%$ & $-8,6 \%$ & $65,5 \%$ & $-1,2 \%$ & $62,0 \%$ & $-4,7 \%$ & $85,2 \%$ & $18,5 \%$ & $86,7 \%$ & $20,0 \%$ & $56,9 \%$ & $-9,8 \%$ & $53,5 \%$ & $-13,2 \%$ & $66,7 \%$ & $1,9 \%$ \\
\hline $40-44$ & $-5,6 \%$ & $62,0 \%$ & $-8,3 \%$ & $73,9 \%$ & $3,6 \%$ & $70,6 \%$ & $0,3 \%$ & $84,8 \%$ & $14,5 \%$ & $86,6 \%$ & $16,3 \%$ & $59,6 \%$ & $-10,7 \%$ & $56,0 \%$ & $-14,3 \%$ & $70,3 \%$ & $0,7 \%$ \\
\hline $45-49$ & $-5,6 \%$ & $65,3 \%$ & $-8,0 \%$ & $75,6 \%$ & $2,3 \%$ & $70,3 \%$ & $-3,0 \%$ & $85,8 \%$ & $12,5 \%$ & $88,6 \%$ & $15,3 \%$ & $63,5 \%$ & $-9,8 \%$ & $61,7 \%$ & $-11,6 \%$ & $73,3 \%$ & $9,2 \%$ \\
\hline $50-54$ & $2 \%$ & $69,1 \%$ & $-6,6 \%$ & $76,5 \%$ & $0,8 \%$ & $78,4 \%$ & $2,7 \%$ & $88,5 \%$ & $12,8 \%$ & $89,1 \%$ & $13,4 \%$ & $67,9 \%$ & $-7,8 \%$ & $66,1 \%$ & $-9,6 \%$ & $75,7 \%$ & $8,6 \%$ \\
\hline $55-59$ & $9 \%$ & $73,6 \%$ & $-3,9 \%$ & $79,9 \%$ & $2,4 \%$ & $77,4 \%$ & $-0,1 \%$ & $88,6 \%$ & $11,1 \%$ & $89,7 \%$ & $12,2 \%$ & $71,0 \%$ & $-6,5 \%$ & $69,9 \%$ & $-7,6 \%$ & $77,5 \%$ & $7,4 \%$ \\
\hline $60-64$ & $0 \%$ & $76,1 \%$ & $-2,9 \%$ & $83,3 \%$ & $4,3 \%$ & $80,9 \%$ & $1,9 \%$ & $87,1 \%$ & $8,1 \%$ & $89,1 \%$ & $10,1 \%$ & $72,8 \%$ & $-6,2 \%$ & $71,0 \%$ & $-8,0 \%$ & $79,0 \%$ & $8 \%$ \\
\hline 65-69 & $9 \%$ & $79,2 \%$ & $-1,6 \%$ & $85,2 \%$ & $4,4 \%$ & $86,0 \%$ & $5,2 \%$ & $88,4 \%$ & $7,6 \%$ & $91,2 \%$ & $10,4 \%$ & $75,3 \%$ & $-5,5 \%$ & $75,7 \%$ & $-5,1 \%$ & $80,8 \%$ & $6 \%$ \\
\hline $70-74$ &, $5 \%$ & $77,1 \%$ & $-1,3 \%$ & $82,1 \%$ & $3,7 \%$ & $81,5 \%$ & $1 \%$ & $86,8 \%$ & $8,4 \%$ & $88,5 \%$ & $10,1 \%$ & $74,9 \%$ & $-3,5 \%$ & $74,5 \%$ & $-3,9 \%$ & $78,4 \%$ & $5,8 \%$ \\
\hline 75-79 & $0 \%$ & $73,2 \%$ & $-2,1 \%$ & $79,1 \%$ & $3,8 \%$ & $78,5 \%$ & $3,2 \%$ & $3,2 \%$ & $7,9 \%$ & $84,5 \%$ & $9,2 \%$ & $71,9 \%$ & $-3,4 \%$ & $70,9 \%$ & $-4,4 \%$ & $75,3 \%$ & $5,0 \%$ \\
\hline $80-84$ &, $5 \%$ & $69,7 \%$ & $2,2 \%$ & $68,5 \%$ & $1,0 \%$ & $68,6 \%$ & $1,1 \%$ & 71,8 & $4,3 \%$ & $76,1 \%$ & $8,6 \%$ & $60,6 \%$ & $-6,9 \%$ & $62,2 \%$ & $-5,3 \%$ & $67,5 \%$ &, $2 \%$ \\
\hline+85 & $8 \%$ & $51,0 \%$ & $3,2 \%$ & $49,6 \%$ & $1,8 \%$ & $52,6 \%$ & $4,8 \%$ & $56,0 \%$ & $8,2 \%$ & $58,5 \%$ & $10,7 \%$ & $43,5 \%$ & $4,3 \%$ & $45,7 \%$ & $-2,1 \%$ & $47,8 \%$ & $3 \%$ \\
\hline TOTAL & $7 \%$ & $62,2 \%$ & $5,4 \%$ & $8,6 \%$ & $0 \%$ & $66,3 \%$ & $-2,3 \%$ & $81,4 \%$ & $12,8 \%$ & $82,8 \%$ & $14,2 \%$ & 59,5 & 9,1 & 58,0 & $-10,6 \%$ & $68,6 \%$ & 9,3\% \\
\hline
\end{tabular}


In the course of the life cycle, it is a period during which there is a rapid increase in participatory behavior, which at that time comes to characterize a strong majority: 66.7\% turnout on average in the 17 voting rounds among the 35-39 age group. As of age 40, turnout continues to increase but at a less sustained pace. Between age 40 and 54, each age group thus shows an average rise in turnout rate of 3 percentage points. The pace of increase is even slower between age 55 and 79: the increase in turnout among each of the age groups then dwindles to an average 1.7 percentage points. In short, voter turnout rises continually and without exception between age 18-24 and 74-79. From this standpoint, four major phases can be identified that follow difference rates of increase: the first phase, from age 18 to 29 , during which turnout is very stable at a low rate ( $52.2 \%$ on average), a second phase, from age 30 to 39, in which turnout rises at a rapid pace, a third period from age 40 to 54 in which this increase continues but at a less sustained rate, to finally exceed $75 \%$ on average (among the 50-54 age group), and a fourth and last period in which turnout stabilizes at a very high and slightly increasing level (ages 55 to 69 ), exceeding $80 \%$ on average among the $65-69$. As of age 70 , the trend reverses and turnout starts to decline. This decrease also follows very different paces. During the seventies it remains controlled: less 2.4 percentage points among the age 70-74 and less 3.1 points among the age 75-79. The result remains an average turnout rate that is still among the highest within the electorate. The oldest old are characterized on the other hand by a steady decline in turnout: less 7.8 percentage points among the age 80-84 and especially, less 19.7 points among the over 84 . As expected, turnout by age group indeed produces a curve that is entirely compatible with the hypothesis of an "age effect" on the chances of voting or the risk of abstaining.

By examining turnout rates we can thus achieve an initial estimation of the relationships between age groups and voting consistency. One way of proceeding is to measure the average deviations from the mean during the 2002-2012 election sequence (table 1 column 26). Column 26 shows an evolution that is relatively congruent with our working hypothesis: deviations from the mean indeed tend to decrease with age to reach a minimum among the 80-84 age group. Among these voters, who form the youngest of the oldest old, the average deviations from the mean recorded over the 17 rounds of balloting examined were only $5.2 \%$, which would seem to indicate great consistency in voting and non-voting from one election to another. Conversely, the 18-24 and the 25-29 age groups show average deviations from the mean that are three times higher: $15.7 \%$ and $14.9 \%$ respectively. This is explained by the considerable mobilization differentials depending on whether a highintensity election is involved or on the contrary the election is of average intensity (regional, legislative, municipal) or of low intensity (European). Thus, for instance, as shown in table 1, the turnout rate for the $25-29$ age group was $81.1 \%$ for the first round of the 2007 presidential election but only $42.8 \%$ for the first round of the legislative elections two months later, then again $42.4 \%$ in the first round of the 2008 municipal elections. By comparison, turnout for the 80-84 age group shows much greater stability: $77.9 \%$ (first ballot of the 2007 presidential election), $67 \%$ (first ballot of the 2007 legislative elections) and 68.5\% (first ballot of the 2008 municipal elections). Whereas the younger segments of the electorate show seemingly erratic turnout rates, alternating peaks and troughs of mobilization (minus 38.7 points between the 2007 presidential and legislative elections), the oldest segments of the electorate are on the contrary characterized by a trend toward the stabilization of turnout rates. This stabilization tends to be confirmed with age, and it is rather remarkable from this standpoint that it remains at a very high level among the over 84 , even as this category is divided almost evenly between voters and non-voters, which increases the statistical likelihood of showing an intermittent voter profile. 
Our sample bases allow us to measure this consistency/intermittence rate at an individual level and thus determine with great precision how it evolves with voter aging. To do so, we took into consideration the three election sequences $(2002,2007$ and 2012) combining two presidential voting rounds and two rounds of legislatives.

Table 2 - Turnout trajectories by age group (2002 presidential and legislative elections)

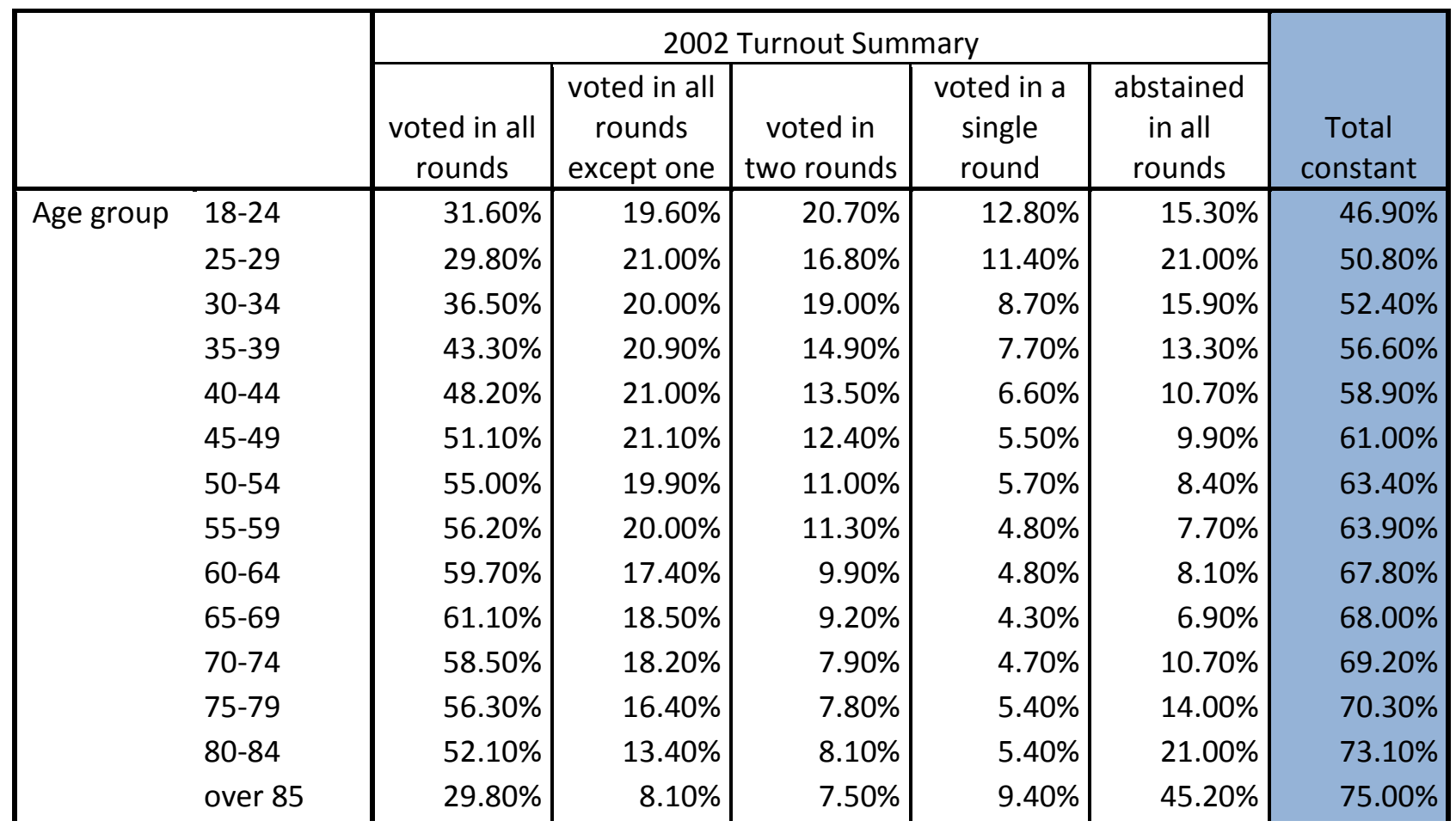


Table 3 - Turnout trajectories by age group (2007 presidential and legislative elections)

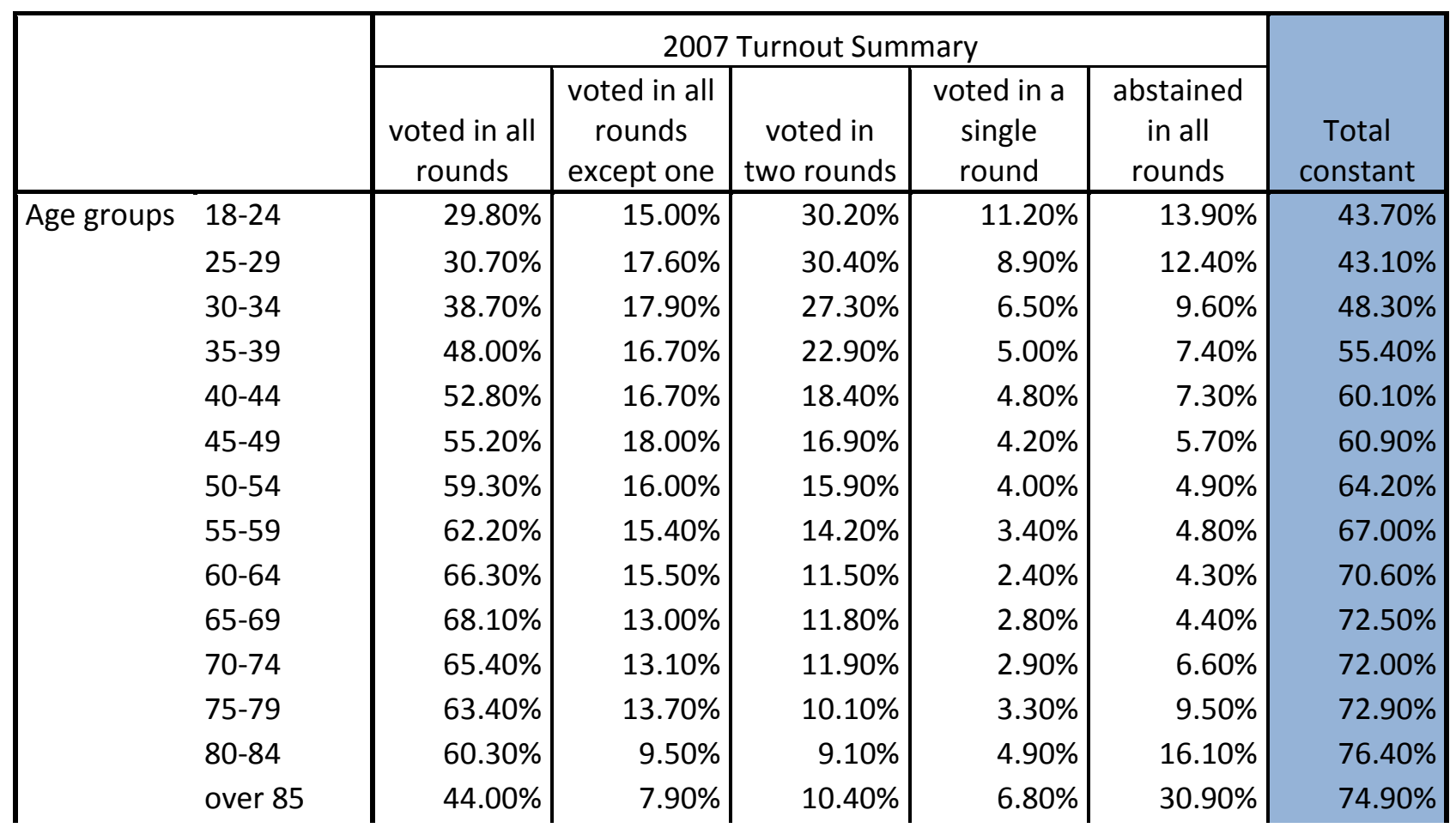

Table 4 - Turnout trajectories by age group (presidential and legislative elections 2012)

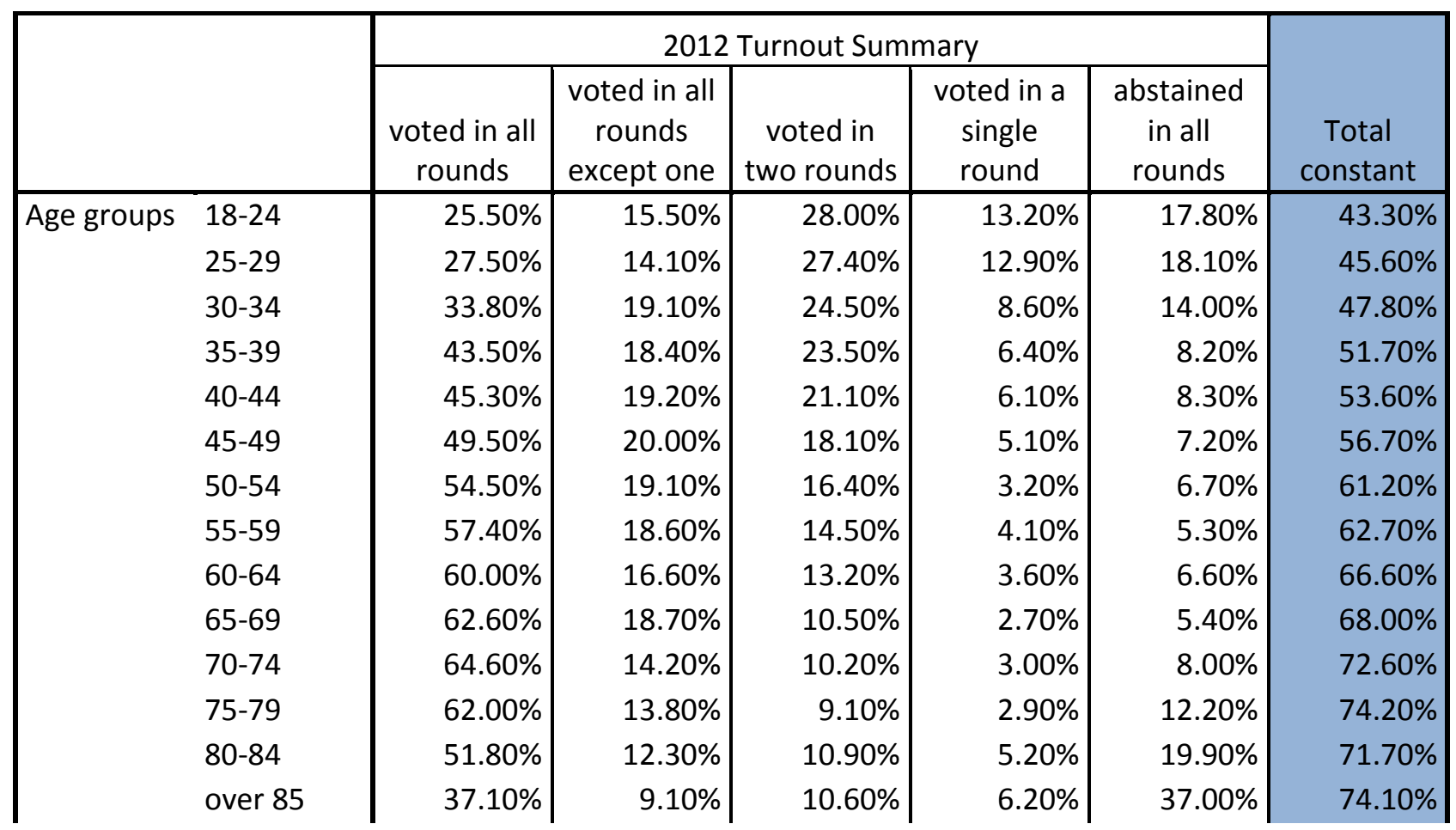


Despite the diversity of political contexts and the renewal of the various age groups in the space of ten years, tables 2, 3 and 4 show considerable stability in the behaviors observed. Of greatest significance for our hypotheses is the fact that behaviors become more and more consistent as voters age. This evolution was perfectly linear in 2002: the oldest age groups are systematically more consistent in their voting behavior than those preceding them. At the top of the age pyramids, the over 84 are thus the most consistent: $75 \%$ of them voted or declined to vote in all the voting rounds without exception. Conversely, in 2002 intermittence is the behavior characteristic of the majority for the 18-24 age group. In 2007 and 2012, measuring voting consistency yields very similar results. On the whole, it increases with age to reach these high levels among the oldest segments of the electorate. This increase is not as perfectly linear as in 2002: in 2012, the 80-84 age group was thus slightly less consistent than the 75-79 age group and in 2007, a very slight decline in consistency was measured among the over 84 . But these slight variations do not alter the general picture: consistency indeed increases with age and the voters who show the most stable behavior are indeed always among the old and even more so the "oldest old" age group. The relative stability over time of this level of consistency should also be pointed out: thus the proportion of consistent voters among the $75-79$ age group is $70.3 \%$ in $2002,72.9 \%$ in 2007 and $74.2 \%$ in 2012 . That of the over 85 is $75 \%$, $74.9 \%$ and $74.1 \%$ respectively. Similarly, the consistency rate among the $18-24$ age group is also quite stable but at opposite levels: $46.9 \%$ in 2002, $43.7 \%$ in 2007 and $43.3 \%$ in 2012. These regularities are observable even when the contexts of these various election sequences were very different. In 2007 and 2012 the younger age groups were much better represented on the electoral rolls than in 2002 . As of the mid-2000s, the automatic registration of 18-year-olds on the electoral rolls had in effect become fully operational, enabling nearly all the young generations to be registered to vote, which was far from previously the case. It should also be pointed out that in 2006 record first-registration or re-registration rates were reached, resulting in the presence of voters on the electoral rolls who heretofore were absent from them. The increased presence of these young voters probably less interested in politics and less inclined on average to perform their civic duties may explain the decline in voting consistency noted in comparison to 2002 among the younger age groups of the electorate. From a political standpoint as well, the contexts were very different from one sequence to the next. In 2002 the presidential election was marked by the presence of an extreme right candidate in the second ballot; in 2007 it was dominated by the personality of UMP leader Nicolas Sarkozy and in 2012 it saw a victory of the left for the first time since 1988. It is interesting to note that these differences in context do not have a significant impact on the logics we have identified behind the rise in voting consistency in relation to voter aging.

Analysis of the three tables also enables us to better identify the turnout logics that determine the intermittent or consistent nature of voting behavior for the various age groups. Within the two younger age groups (18-29), the proportion of consistent voters is particularly low: $29 \%$ on average in the three sequences. This low degree of consistent voting is indeed one of the main voting particularities of the young electorate. A considerable proportion of these young voters only participated in two voting rounds: $29 \%$ on average in the 2007 and the 2012 sequences. They are mainly voters who cast a ballot only in the most mobilizing election - the presidential - and do not vote in the legislative elections. The remaining $40 \%$ is rather evenly divided between the nearly consistent who abstain only once, the near-non-voters who vote only in one round (almost always a presidential round) and the consistent non-voters who do not participate in either the legislatives or 
even the presidential election. The rise in consistent behavior we subsequently notice with the aging of the electorate follows two distinct paths. Whether in 2002, 2007 or 2012, up until age 70, it takes the route of a strong increase in consistent voting and the concomitant decrease in consistent nonvoting and low participatory behavior (vote in only one round and in only two rounds). The rise in turnout, becoming increasingly consistent, thus explains the tendency toward the stabilization of voting behavior noted between the ages of 29 to 70 . After that age, this still clear stability is also rooted in the rise in consistent non-voting. Whether in 2002, 2007 or 2012, consistent non-voting turns slightly upward as of age 70 before reaching very high levels among the 80-84 age group and even higher among the over 84 . While during the period studied, the average turnout rates of the 1829 age group and the over 84 are fairly similar (cf. table 1), they actually correspond to a radically different practical relationship toward voting. The average turnout rate among young voters (52.1\%) is the result of very intermittent behavior combining, for many of them, a vote in high-intensity elections such as the presidential campaign and massive abstention in other elections. The adoption of intermittent behavior does not explain average turnout rate of the over 84 (47.8\%): scarcely a quarter of them in this age bracket has not adopted an attitude of consistency over the three sequences studied. This average rate is the consequence of a shift to systematic abstention among a significant portion of these very old voters.

These observations all support the hypothesis of an "age effect" having biological causes that weighs decisively on the logics of participation, particularly among the very old who are the focus of this study. The curve of systematic abstention thus fits well with the existence of such an effect. The dynamics are remarkably similar in 2002, 2007 and 2012. Systematic abstention stabilizes at very low levels between age 50 and 70 . It is still as of age 70 that there is a noticeable upward turn in this systematic abstention. And it is after age 84 that it becomes one of the main characteristics of very old voters. Such observations reinforce the hypothesis that the primary cause of changes in voter turnout affecting this age group are to be sought in the physical deterioration and the fall into dependency of an ever-growing fraction of very old adults. Those who remain able to vote remain consistent voters until the deterioration resulting from the onset of very old age forces them to give up the practice of voting, usually permanently.

It remained to be seen whether age didn't work as a variable masking other factors that might turn out to be overdeterminant. Different age groups are in fact known to be very different from a social and cultural standpoint. It could thus be these differences, rather than the effect of aging, that explain the evolution in voting behavior measured by bivariate analysis (Dalton, 2002, Denni, 2007). To control for this possibility, we performed binary logistic regressions for each of the 17 voting rounds used as empirical data for this study. The variable we sought to explain each time was voter turnout. For independent variables we chose variables that were available in 2002, in 2007 as well as in 2012 so as to make accurate comparisons. These variables were also chosen because they are at once factors that influence voter turnout and because they are unevenly spread over the various phases that make up the life cycle and from one generation to the next, hence in the age groups we examine. The first of these variables is gender. It was all the more important to fit it into our model as, given the differences in life expectancy between the sexes, the oldest old and especially the over 84 are far more frequently women than men: in $2007,67.8 \%$ of the over 84 on the electoral rolls were women. Consequently, the "very old age effect" might actually be overdetermined by a "gender effect." Likewise, the relationship to work and economic activity is largely determined by one's position in the life cycle. Younger people and the elderly thus have much higher probabilities of being 
economically inactive than those between age 30 and 60 . This is why we include a variable in our model identifying the voter's "profession and socio-occupational category" to determine among other things whether the inactive or retired status does not overdetermine the age effect previously identified. Educational level is also very unevenly distributed among the various age groups. This is more a "generational effect" resulting from the fact that the older age groups did not benefit from the democratization of secondary and higher education, unlike the youngest segments of the electorate. It being a determinant factor of politicization and voter turnout, we also worked it into our regression model. Lastly, an individual's legal marital status also evolves over the course of the life cycle and from one generation to the next. The youngest group is usually single and the oldest usually widowed. As this variable is an indicator, albeit an indirect and imperfect one, of a voter's contextual situation and as this situation influences voter turnout, we also worked it into our model. It would have been preferable to have a variable available that pertains to the form of cohabitation within the household that would allow us to identify individuals living alone, individuals living in institutions such as homes for young workers or retirement homes, and individuals living with a partner (whether legally married or not). Unfortunately, such a variable exists only in the 2012 database. In any event, the variables available that we have just described already enable us to test whether age continues to have an effect on the likelihood of voter turnout once controlled for the effects of sociological variables. The results of the 17 regressions performed are presented in table 5 . Only the coefficients and the odds ratio associated with the various age groups were retained. 
Table 5 - coefficients and odds ratio by age group established for 17 voting rounds between 2002 and 2012

\begin{tabular}{|c|c|c|c|c|c|c|c|c|c|}
\hline \multirow{2}{*}{ 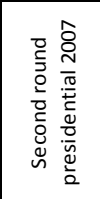 } & \multirow{2}{*}{ 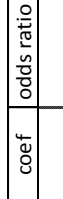 } & & \multirow{2}{*}{ 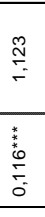 } & \multirow{2}{*}{ 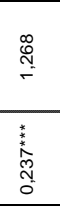 } & \multirow{2}{*}{ 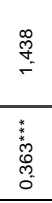 } & \multirow{2}{*}{ 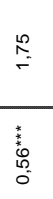 } & \multirow{2}{*}{ 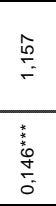 } & \multirow{2}{*}{ 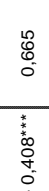 } & \multirow{2}{*}{ 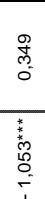 } \\
\hline & & & & & & & & & \\
\hline \multirow{2}{*}{ 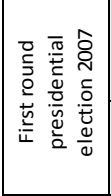 } & $\mid$\begin{tabular}{|c|}
0 \\
$\frac{0}{0}$ \\
$\frac{0}{0}$ \\
$\frac{0}{0}$
\end{tabular} & & $\stackrel{\infty}{\stackrel{0}{\rightleftarrows}}$ & $\stackrel{\mathbb{\sigma}}{=}$ & 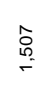 & 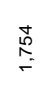 & $\stackrel{\stackrel{9}{్}}{=}$ & $\begin{array}{l}0 \\
\vdots \\
0 \\
0\end{array}$ & 蒡 \\
\hline & 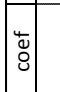 & & 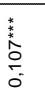 & $\begin{array}{l}\frac{1}{1} \\
\frac{1}{0} \\
\end{array}$ & $\frac{1}{4}$ & 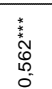 & 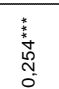 & 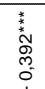 & 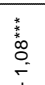 \\
\hline \multirow{2}{*}{ 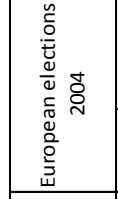 } & 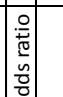 & & 芯 & 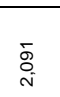 & 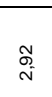 & 总 & 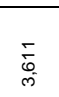 & 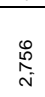 & ָָּ \\
\hline & \begin{tabular}{|l|} 
\\
$\mathrm{o}$ \\
$\mathrm{g}$
\end{tabular} & & 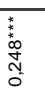 & 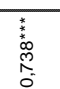 & 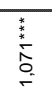 & 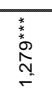 & 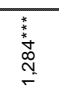 & 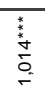 & 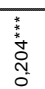 \\
\hline \multirow{2}{*}{ 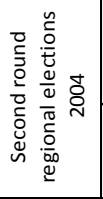 } & 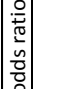 & & 总 & î̀ & 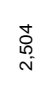 & $\begin{array}{l}\infty \\
\stackrel{\infty}{N} \\
\end{array}$ & 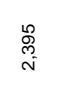 & 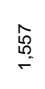 & 产 \\
\hline & 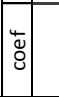 & & 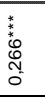 & 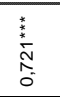 & 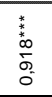 & 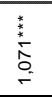 & $\begin{array}{l}1 \\
\vdots \\
0 \\
0 \\
0 \\
0 \\
0\end{array}$ & 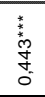 & 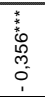 \\
\hline \multirow{2}{*}{ 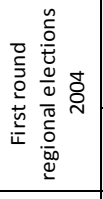 } & $\mid$\begin{tabular}{|c|}
$\frac{0}{0}$ \\
$\frac{0}{0}$ \\
$\frac{0}{0}$
\end{tabular} & & 惌 & $\begin{array}{l}\stackrel{N}{0} \\
\stackrel{\sim}{\sim}\end{array}$ & $\begin{array}{l}\stackrel{8}{\circ} \\
\text { N }\end{array}$ & $\stackrel{\hat{N}}{\hat{N}}$ & $\begin{array}{l}\stackrel{0}{0} \\
\stackrel{\leftrightarrow}{N}\end{array}$ & 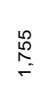 & $\begin{array}{l}\text { 员 } \\
\text { م. }\end{array}$ \\
\hline & 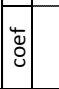 & & 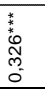 & $\begin{array}{l}t_{0}^{0} \\
0 \\
0 \\
0 \\
0\end{array}$ & 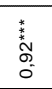 & $\stackrel{1}{-}$ & $\begin{array}{l}\text { to } \\
\text { o. } \\
0 \\
0\end{array}$ & 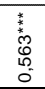 & 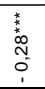 \\
\hline \multirow{2}{*}{ 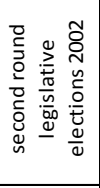 } & 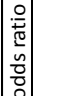 & & 곯 & $\begin{array}{l}\stackrel{\hat{\infty}}{\stackrel{-}{-}} \\
-\end{array}$ & $\begin{array}{l}\bar{\delta} \\
\stackrel{i}{i}\end{array}$ & 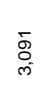 & $\begin{array}{l}\text { 总 } \\
\text { ల) }\end{array}$ & 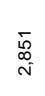 & 兽 \\
\hline & & & 荌 & 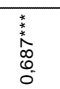 & $\begin{array}{l}\text { 麦 } \\
\text { o. } \\
0 \\
0\end{array}$ & $\begin{array}{l}\frac{1}{\vdots} \\
\stackrel{N}{N} \\
\end{array}$ & 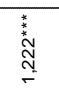 & 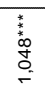 & 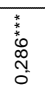 \\
\hline \multirow{2}{*}{ 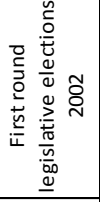 } & \begin{tabular}{|l|}
$\frac{0}{\mathrm{t}}$ \\
$\frac{\mathrm{v}}{\mathrm{z}}$ \\
\end{tabular} & & ָָָ & 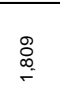 & $\underset{\substack{0 \\
N}}{0}$ & 商 & 恿 & 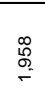 & 今. \\
\hline & \begin{tabular}{|l|}
\multicolumn{4}{|c|}{} \\
$\mathrm{o}$
\end{tabular} & & 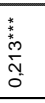 & 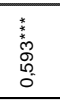 & $\begin{array}{l}\text { s. } \\
\text { s. } \\
\end{array}$ & 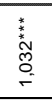 & 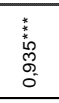 & \begin{tabular}{l}
1 \\
\multirow{2}{*}{} \\
0 \\
0 \\
0
\end{tabular} & $\begin{array}{c}\vdots \\
\vdots \\
0 \\
0 \\
0\end{array}$ \\
\hline \multirow{2}{*}{ 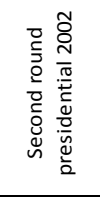 } & $\mid \frac{0}{0}$ & & 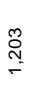 & & 总 & 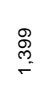 & $\stackrel{0}{\circ}$ & 总 & 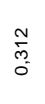 \\
\hline & \begin{tabular}{|l|} 
\\
$\stackrel{\mathrm{g}}{ }$
\end{tabular} & & 象 & 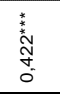 & 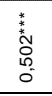 & $\begin{array}{l}\vdots \\
0 \\
0 \\
0 \\
0\end{array}$ & : & $\begin{array}{l}\frac{1}{4} \\
0 \\
0 \\
0 \\
0 \\
\end{array}$ & $\begin{array}{l}\frac{1}{4} \\
0 \\
0 \\
\end{array}$ \\
\hline \multirow{3}{*}{ 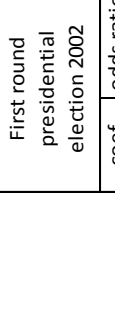 } & 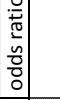 & & $\stackrel{m}{\stackrel{m}{=}}$ & $\stackrel{g}{\stackrel{0}{+}}$ & 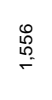 & 䓌 & 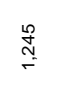 & $\stackrel{n}{\stackrel{0}{r}}$ & 曽 \\
\hline & 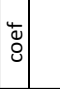 & & $\begin{array}{l}1 \\
\vdots \\
0 \\
0 \\
0\end{array}$ & 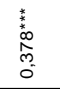 & \begin{tabular}{l}
\multirow{2}{*}{} \\
\multirow{3}{*}{} \\
\multirow{2}{*}{}
\end{tabular} & $\begin{array}{l}t \\
0 \\
0 \\
0 \\
0\end{array}$ & 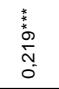 & $\begin{array}{l}1 \\
0 \\
0 \\
0 \\
0\end{array}$ & 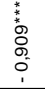 \\
\hline & & 离 & 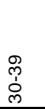 & $\begin{array}{l}\text { o } \\
\text { o } \\
\end{array}$ & $\begin{array}{l}0.00 \\
0 \\
0 \\
0\end{array}$ & $\begin{array}{l}\mathbf{0} \\
\vdots \\
0\end{array}$ & $\begin{array}{l}\hat{2} \\
\dot{1} \\
\end{array}$ & $\begin{array}{c}\mathbf{0} \\
\mathbf{0} \\
\dot{\infty} \\
\end{array}$ & 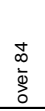 \\
\hline
\end{tabular}




\begin{tabular}{|c|c|c|c|c|c|c|c|c|c|}
\hline \multirow{2}{*}{ 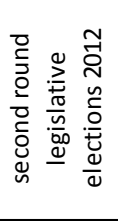 } & $\mid$ & & $\stackrel{t}{\stackrel{ \pm}{*}}$ & 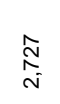 & 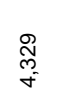 & \begin{tabular}{l}
$\stackrel{\infty}{\infty}$ \\
\multirow{\sigma}{*}{}
\end{tabular} & 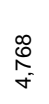 & $\underset{j}{N}$ & 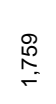 \\
\hline & 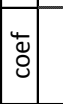 & & 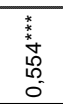 & 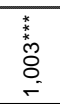 & 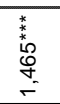 & 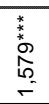 & 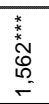 & 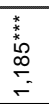 & 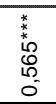 \\
\hline \multirow{2}{*}{ 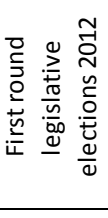 } & 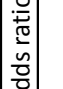 & & $\begin{array}{l}\bar{\sigma} \\
\stackrel{0}{ז}\end{array}$ & $\begin{array}{l}\bar{\sigma} \\
\stackrel{0}{\sim}\end{array}$ & $\begin{array}{l}\infty \\
\stackrel{\infty}{\infty} \\
\stackrel{\sim}{+}\end{array}$ & $\underset{\substack{\sigma \\
\dot{f}}}{ }$ & i⿱口口) & 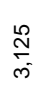 & 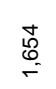 \\
\hline & 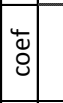 & & 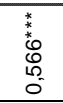 & $\begin{array}{l} \\
0 \\
0 \\
0 \\
0 \\
0 \\
0\end{array}$ & 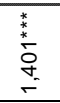 & 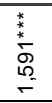 & 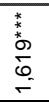 & 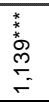 & $\begin{array}{l}\text { 恙 } \\
\text { o. } \\
0 \\
0\end{array}$ \\
\hline \multirow{2}{*}{ 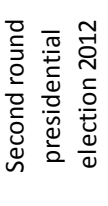 } & $\mid$\begin{tabular}{|c|c}
0 \\
$\frac{0}{0}$ \\
$\frac{0}{0}$ \\
$\frac{0}{0}$
\end{tabular} & & 总 & $\underset{\substack{\infty \\
\sim}}{ }$ & $\begin{array}{l}\infty \\
\stackrel{\infty}{\infty} \\
\stackrel{\infty}{\infty}\end{array}$ & ్ָ心 & 怘 & 荪 & $\stackrel{8}{0}$ \\
\hline & 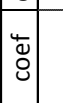 & & $\begin{array}{l}\text { : } \\
\text { o } \\
\text { o } \\
0\end{array}$ & 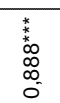 & 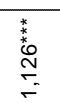 & 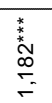 & 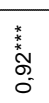 & 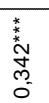 & 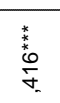 \\
\hline \multirow{2}{*}{ 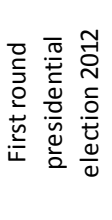 } & $\mid$\begin{tabular}{|c|} 
\\
$\frac{0}{0}$ \\
$\frac{0}{0}$ \\
$\frac{0}{0}$ \\
\end{tabular} & & $\stackrel{8}{:}$ & $\bar{\sim}$ & $\stackrel{\infty}{\stackrel{\infty}{\sim}}$ & $\underset{\sim}{\stackrel{\Omega}{\sim}}$ & 吕 & $\underset{\substack{0\\
}}{ }$ & 芯 \\
\hline & 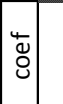 & & 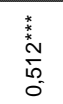 & 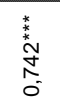 & 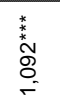 & 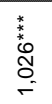 & $\begin{array}{c}\vdots \\
\vdots \\
\vdots \\
0 \\
0 \\
0 \\
0\end{array}$ & 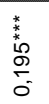 & 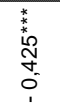 \\
\hline \multirow{2}{*}{ 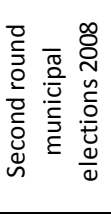 } & $\left|\begin{array}{|c|} \\
\frac{0}{0} \\
\frac{\pi}{2} \\
\frac{0}{0}\end{array}\right|$ & & & $\begin{array}{l}\stackrel{\infty}{\infty} \\
\stackrel{N}{N}\end{array}$ & $\frac{\hat{N}}{\frac{N}{n}}$ & 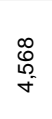 & 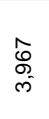 & $\underset{\substack{\mathbb{N} \\
\text { N }}}{ }$ & $\infty$ \\
\hline & 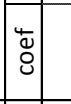 & & 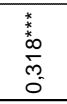 & 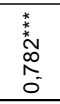 & 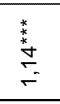 & 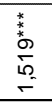 & 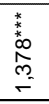 & 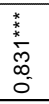 & 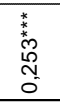 \\
\hline \multirow{2}{*}{ 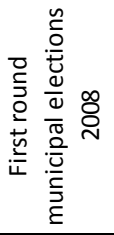 } & 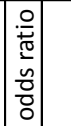 & & $\underset{\sim}{\text { 导 }}$ & 总 & 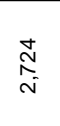 & $\begin{array}{l}\text { बे } \\
\text { o. }\end{array}$ & 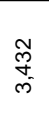 & $\stackrel{\infty}{\stackrel{\infty}{\sim}}$ & \\
\hline & 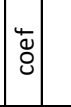 & & $\begin{array}{l}\text { t. } \\
\text { o. } \\
0 \\
0\end{array}$ & 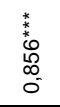 & 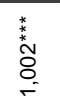 & $\begin{array}{l}\text { 素 } \\
\text { o } \\
\stackrel{+}{5}\end{array}$ & 䒫 & 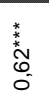 & $\begin{array}{l}\text { o. } \\
0 \\
0 \\
0\end{array}$ \\
\hline \multirow{2}{*}{ 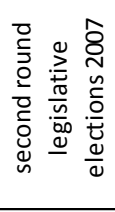 } & $\mid$ & & 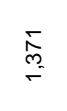 & 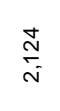 & $\frac{\stackrel{d}{N}}{\stackrel{\infty}{\infty}}$ & \begin{tabular}{l}
$\infty$ \\
$\substack{\infty \\
\hdashline}$ \\
$\forall$
\end{tabular} & 荬 & $\underset{\substack{\infty \\
m}}{\stackrel{m}{2}}$ & $\bar{N}$ \\
\hline & $\mid \begin{array}{l}\mid \\
\mathrm{d} \\
\mathrm{d}\end{array}$ & & 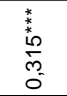 & 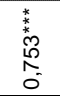 & 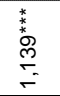 & 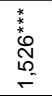 & 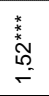 & 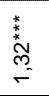 & $t_{0}^{*}$ \\
\hline \multirow{2}{*}{ 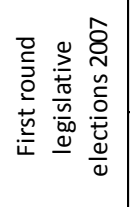 } & $\mid$ & & 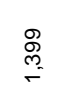 & $\begin{array}{l}\stackrel{N}{N} \\
\stackrel{N}{N}\end{array}$ & 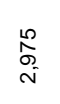 & $\stackrel{0}{\stackrel{0}{\sigma}}$ & 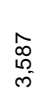 & 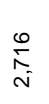 & 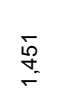 \\
\hline & 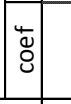 & & $\begin{array}{l}\text { : } \\
\text { co } \\
0 \\
0 \\
0\end{array}$ & $\begin{array}{l} \\
\vdots \\
\vdots \\
0 \\
0 \\
0\end{array}$ & 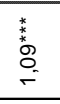 & 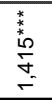 & 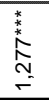 & $\begin{array}{l}\text { 意 } \\
\text { o } \\
\text { o. } \\
口\end{array}$ & $\stackrel{\infty}{\infty}$ \\
\hline & & 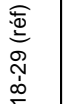 & 艿 & $\frac{o}{+}$ & 官 & 8 & $\dot{d}$ & o. & \\
\hline
\end{tabular}

${ }^{* * *} \mathrm{p}<.001,{ }^{* *} \mathrm{p}<.05,{ }^{*} \mathrm{p}<.1$ 
The results obtained also support our initial hypotheses. We first note that the regression coefficients associated with the various age groups are always significant and in nearly all cases even meet a significance threshold of 0.000 . This initial observation shows that the sociological variables included in our model did not eliminate the effect of age on the likelihood of voter turnout. Age thus does not operate solely as a variable that masks differences in gender, marital status, educational level or profession and social category.

By examining the odds ratios associated with the various age groups, we can further refine the results presented previously. As predictable given the intermittent behavior of the younger age groups, these odds ratios evolve considerably depending on the intensity of the election, going so far as to reverse when moving from a very high-intensity election such as the presidential to average and low-intensity elections such as municipal, legislative, regional or even European elections. In the rounds of presidential elections, the over 84 were much less likely to participate in the vote than the 18-29 age group (the baseline modality): thus during the two voting rounds of the 2007 presidential election for which turnout reached a record high, the likelihood that the over 84 would vote was three times less than those age 18-29 once controlled for the effects of other sociological variables. For all other types of election, the relationship tends to be inverted. The oldest age groups (80-84 and the over 85 ) have probabilities of voting in these situations of lesser intensity that are closer to or even exceed the voting probabilities of the age 18-29. The three sequences combining presidential elections and legislative elections examined previously provide a good illustration of this phenomenon. While the voting probabilities of young voters are much higher in the presidential election, the relationship is inverted with the drop in election intensity characteristic of legislative elections held six weeks later: out of the 6 voting rounds discussed, the odds ratios of the over 85 is only once very slightly lower than 1 (in the first round of the 2002 legislative elections, when it is 0,920 ). In the five other voting rounds examined, it is between a minimum of 1.331 (second round of the 2002 legislative election) and a maximum of 1.821 (second round of the 2007 legislative elections). The over 84 initially have a voting probability that is three times lower in the presidential election, and in the space of six weeks, this probability becomes nearly two times higher in the legislative elections.

\section{Discussion}

The body of results obtained using the INSEE sample bases turns out to be consistent with our initial hypothesis. They describe a relationship between age and voter turnout that obeys the following logic: as voters age, they move from essentially intermittent behavior altering abstention and participation to increasingly consistent attitudes. This stabilization takes the form of a marked increase of voter turnout: when they reach the early years of old age, the large majority of citizens are quasi-consistent voters by that time, and systematic abstention has become a residual behavior. The overwhelming shift to abstention for the oldest fraction of the electorate in no way invalidates this model. On the contrary, "oldest old" voters display a level of attitudinal consistency equal to and often even higher than their "younger old" counterparts. When they stop voting, it is due to a shift to abstention that in most cases is permanent.

Our regression model confirms this explanatory framework and thus enables us to better grasp the relations between age and probabilities of voter turnout. Given the very uneven distribution of 
inclinations toward intermittence and consistency within them, the various age groups are very unevenly sensitive to election intensity. This relationship can be formulated as follows: the more an age group shows inclinations toward intermittence, the more its voter turnout depends on the level of intensity of the election considered. Conversely, the more an age group shows inclinations toward consistency, the less its turnout is a function of the intensity of the election.

The set of regression coefficients presented in table 5 confirms this relationship. Young voters turn out in large numbers for the sole very high-intensity election in France, which is the presidential election. On the other hand, the surge in mobilization due to the presidential election is much lower moving up through the age groups because their behavior is increasingly consistent and so less affected by the level of election intensity. In the context of a presidential election, it is logical that differences in the likelihood of getting out to vote between young and older age groups shrinks. It is also logical that in comparison, this same likelihood of voting declines among the oldest segment of the electorate, a substantial portion of which have become consistent non-voters and thus can no longer be mobilized even in the prospect of a presidential election. It is also logical that the drop in election intensity can, depending on its degree, lessen, and even reverse the direction of odds ratios calculated for a presidential election: in medium-high intensity ballots (2004 regional elections for instance) the likelihood that young people will vote becomes much lower than for those between age 30 and 70, and tends to balance out with the voting probability of the oldest old precisely because these various age groups are fairly consistent in terms of turnout and hence far less sensitive to election intensity. As election intensity weakens, the inversion of odds ratios becomes more pronounced, such that the likelihood that the over 84 will vote becomes greater than that of the 1829 age group. Within the electorate, the voting probabilities among the over 84 compared to those under 30 are thus inversely proportional to the mobilizing potential of the election.

Consequently, the effect of age on turnout cannot be determined without taking into account the intensity of the election. The higher the intensity, the stronger the probability that the youngest voters will vote, especially in comparison to the oldest category of voters, whose behavior tends with age to become more independent from election campaign intensity. Conversely, the lesser the intensity, the more the voting probability of the youngest age group diminishes with respect to other age groups and even compared to the oldest old voters. This relationship naturally carries a whole set of political consequences because the rise in abstention necessarily produces a de facto aging of the electorate. It is moreover well known that seniors have very different political orientations than the youngest voters.

The strength of these results lies in the size of samples used and the accuracy of the data, particularly those related to age and voter turnout, which were taken directly from signatures on the electoral registers on election day. It also resides in the repetition of the observations that made it possible to establish the relationships between age and turnout: 17 rounds of voting of very different intensity examined between 2002 and 2012.

Our sample bases have limitations, as well, however, particularly as regards the explanatory variables available. We have no information, for instance, about the size of voters' wealth, although it is known to be distributed very differently among age groups, it being the result of accumulation that occurs throughout the entire life cycle. More unfortunately, we have no information regarding the 
relationship to religion and politics. In our models we thus cannot include variables pertaining to religious belief and practice, which are known to vary considerably by generation. Similarly, we cannot take into account politicization and party identification, which are known to evolve over the course of the life cycle and are naturally important factors in voter turnout.

The availability of such variables would not invalidate the existence of a relationship between age groups and voter turnout, but it would enable us to better test what enters into this "age effect" that can be measured with the data we have. The aim would be to determine the explanatory factors for the rise in voting consistency with age. Several types of explanations can be brought into play here. Differences in behavior by age group are traditionally explained in the literature by a "generational effect" (Miller and Shanks 1996, Blais et al. 2004, Clarke et al. 2004, Franklin 2004) or a "life cycle effect" (Bean C. 2005, Knoke, Hout, 1976). While it cannot be ruled out, the generational effect, given the timeframe to which our observations apply (10 years) seems fairly unlikely. Indeed, if it were to reveal a generational logic, it would be hard to understand the linearity of the rise in consistency. But in order to test this, our model would have to be replicated over much longer sequences: at least 30 years, in other words a "biological generation." ${ }^{1}$

Explanations are probably to be sought, rather, in "life cycle effects." To carry out this analysis, it would be useful to distinguish three dimensions of this effect, even if they are largely interdependent: 1) a sociological dimension, 2) a cognitive and psychological dimension and 3) a biological dimension.

This effect may thus be brought to bear on a specifically sociological dimension: in the course of the life cycle, individual's material living conditions change, resulting in return in a modification of their practices and behavior. For instance, they accumulate wealth or start living with a partner, have children, work, and then leave the workforce, and so on. These transformations are as many factors that are known to influence the probability of voter turnout. Regression analyses should make it possible to test whether these variables pertaining to the sociological effects of the life cycle absorb the age effect and thus help to better interpret it. We are missing some of these variables: wealth, form of cohabitation within the household for 2002 and 2007 and improper registration. However, the variables available enabled us to show that the age effect does not boil down to a "gender effect," a " marital status effect," an "occupational effect" or an "educational level effect." Subject to tests on the basis of sociological variables associated with the various stages of the life cycle, the results of our regression suggest seeking an explanation for the rise in voting consistency either in 1) the cognitive and psychological effects of aging, or in 2) the direct and indirect effects of physical deterioration related to very old age.

It has long been established that the cognitive and psychological dimension of the relationship to politics changes over the course of the life cycle. Politicization thus tends to heighten with age to

\footnotetext{
${ }^{1}$ It is not impossible, however, that generational factors come into play in the turnout rate of the various age groups. Generation renewal as well as changes in the political context may also lead to a decline in the proportion of consistent voters by age group (Tiberj ref). Such an evolution would not be incompatible with a sustained trend of increased consistency with age, but to a lesser degree than those noted in the early 2000 s.
} 
reach a threshold among the middle-aged working population and young retirees, forming a curve that is fairly similar in shape to that of voter turnout. By the same token, a psychological phenomenon such as party identification is formed and reshaped throughout the entire life cycle: initial identification in childhood, crystallization in adulthood and tendency toward reinforcement with age. These are variables that have an influence on voter turnout that we did not have the means to test in this study. Research in social psychology has also brought to light the repetitive tendency of behavioral habits over time, solidifying as individuals age (Ajzen 2002, Goerres 2009). This research applies to regular, if not everyday, practices. But according to Achim Goerres, it could also apply to voting and thus account for the general rise in turnout with age that is noted in all European democracies. While such interpretations are patently compatible with the linear rise in voting consistency we have found in the case of France, our variables do not enable us to control for it directly.

Lastly, our findings also seem to call for explanations resorting to directly biological effects of aging. In both 2002 and 2007 as well as in 2012, a rise in consistent non-voting is noted as of age 70 . But above all, we note a very rapid rise in consistent non-voting among the over 80 and even more so among the over 84 . These evolutions occur at very precise moments in the life cycle that do not coincide with any particular social time but rather a biological time and its social consequences. After 80 and even more after 84 , the risks of physical deterioration that can lead to falling into dependency with its ensuing consequences (isolation, institutionalization, etc.) increase considerably, resulting in abandoning what was previously consistent voting turnout and a shift into non-voting that becomes permanent (Thomas 1996). Future research would stand to gain by generating data that would make it possible to test these explanations more directly

\section{Conclusion}

Our findings lead us to distinguish two main types of non-voting. The first stems from intermittent voting behavior that is primarily a characteristic of young voters. Another type has to do with the inability to vote due to physical weakness and characterizes the oldest segments of the electorate. These two types of non-voting have nothing in common. The first characterizes voters who have not yet integrated the norm of participation and need to be actively mobilized to go to the polls. The second type on the contrary characterizes voters who up until a given point have tended to vote consistently, but whose slide into dependency keeps them permanently away from the polls. The first type of non-voting is in no way unpreventable and can reduced by intense get-out-the-vote campaigns. The second is largely independent from political activity and media coverage. Given the aging of the electorate, it is bound to spread and thus become an increasingly decisive factor as regards the evolution of non-voting in our societies. 
Bibliography

- Ajzen I., 2002, "Residual Effects of Past on Later Behavior : Habituation and Reasonned Action Perspectives", Personality and Social Psychology Review 6 (2): 107-22.

- $\quad$ Bean C., 2005, An Age Old-Question: Are Relationships Between Age and Political Attitudes a Consequence of Life-Cycle or Cohorts-Replacement Effects?, Paper presented to the Social Change in the 21th century, Queensland University of Technology, 28 October 2005.

- Beck P., Jennings K., 1982, "Pathways to participation ", The American Political Science Review, 76 (1), p 94-108.

- Blais A., Gidengil E., Nevitte N., Nadeau R., 2004, "Where Does Turnout Decline Come From?", European Journal of Political Research 43: 221-36.

- $\quad$ Buds P., Stokes D., 1969, Political change in Britain, New York, Saint Manin's Press.

- Converse P., 1976, The Dynamics of Party Support: Cohort-analysing Party Identification, Beverly Hills, Sage Publications.

- Campbell A., Converse P., Miller W. E.; Stokes D., 1960, The American Voter, Wiley, New York.

- $\quad$ Clarke H.D., Sanders D., Stewart M.C., Whiteley P.F., 2004, Political Choice in Britain. Oxford: Oxford University Press.

- $\quad$ Cutler, Neal E., 1969-70, "Generation, Maturation, and Party Affiliation: a Cohort Analysis", Public Opinion Quarterly Volume 33, Issue 4, pp. 583-588.

- $\quad$ Cutler, Neal E., Vern Bengtson L, 1974, "Age and Political Alienation: Maturation, Generation and Period Effects", The Annals of the American Academy of Political and Social Science, September, 415: 160-175,

- $\quad$ Dalton, R., 2002, Citizen Politics: Public Opinion and Political Parties in Advanced Western Democracies, New York/London: Chatam House.

- Denni B., 2007, " Participation politique et vote des seniors à l'élection présidentielle de 2007 », Gérontologie et société, n 120, pp. 29-50

- Denni B., 2012 "Comportement politique et préférences électorales des seniors en 2012 ", Gérontologie et société, $\mathrm{n}^{\circ} 143$, pp. 39-50.

- $\quad$ Franklin M.N., 2004, Voter Turnout and the Dynamics of Electoral Competition in Established Democracies. Cambridge: Cambridge University Press.

- Goerres A., 2009, The Political Participation of Older People in Europe. The Greying of our Democracies, Basingstoke, Palgrave Macmillan.

- $\quad$ Knoke D., Hout M., 1976, «Cohort analysis futile quest : statistical attempts to separate age, period and cohort effects ", American Sociological Review, 41, pp. 900-908. 
- $\quad$ Lipset, S.M., Lazarsfeld, P.F., Barton, A.H., Linz, J.J. 1954, "The psychology of voting: An analysis of political behavior". In G. Lindzey (Ed.), Handbook of social psychology: Vol. II, pp. 1124-1175.

- Miller W.E., Shanks J.M., 1996, The New American Voter, Cambridge, MA/London, UK : Harvard University Press.

- $\quad$ Popkin S. L., 1991, The Reasoning Voter, Chicago University Press, Chicago.

- $\quad$ Riley M., Foner A., 1968, Aging and society, New York Sage publication.

- $\quad$ Thomas H., 1996, Vieillesse Dépendante et Désinsertion Politique, Paris, L'Harmattan.

- Tilley J., 2002, Political Generations and Partisanship in the UK, 1964-1997, Journal of the Royal Statistical Society. Series A (Statistics in Society), Vol. 165, No. 1, pp. 121-135

- Verba S., Nie N., 1972, Participation in America: Political democracy and Social Equality, New York, Harper and Row.

- Verba S., Nie N. H, Petrocik J. R., 1976, The Changing American Voter, Harvard University Press, Harvard. 